\title{
LOGÍSTICA DE UMA MONTADORA AUTOMOBILÍSTICA COMPLETELY KNOCKED DOWN ${ }^{1}$
}

\section{LOGISTICS OF A COMPLETELY KNOCKED DOWN AUTOMOBILE ASSEMBLY PLANT}

\author{
Larissa Diniz Freitas* E-mail: lari diniz@hotmail.com \\ Nilton Luiz Menegon* E-mail: menegon@dep.ufscar.br \\ Miguel A. Bueno da Costa*E-mail: mbcosta@ufscar.br \\ *Universidade Federal de São Carlos (UFSCar), São Carlos/SP
}

\begin{abstract}
Resumo: Este trabalho analisa a cadeia de suprimentos de uma montadora automobilística que opera em regime Completely Knocked Down (CKD). O objetivo é apresentar e discutir as condicionantes operacionais que essa cadeia gera sobre as operações produtivas da montadora em questão. A pesquisa, realizada por meio de um estudo de caso, considerou a cadeia a partir da solicitação de importação das peças até a distribuição dos carros montados. Foi observado que a montadora sofria uma série de condicionantes que afetavam diretamente suas operações logísticas. Esses condicionantes têm origem em três lógicas operacionais: a Lógica do Emitente, a Lógica do Destinatário e a Lógica da Distribuição. Foram identificados os conflitos existentes entre essas lógicas, os quais interferem nas operações e nos limites físicos da montadora. Essa pesquisa introduziu uma nova perspectiva de análise de um sistema CKD.
\end{abstract}

Palavras-chave: Sistema CKD. Cadeia de suprimentos. Lógicas operacionais. Estratégia. Indústria automobilística.

Abstract: This work analyzes the supply chain of an automobile assembly plant operating under Completely Knocked Down (CKD). The objective is to present and discuss the operational constraints that this supply chain produces on the production operations of the referred automaker. The research, which was conducted through a case study, considered the chain from the importation request of pieces until the distribution of the assembled cars. A series of constraints that directly affected the assembler's logistics operations were observed. These constraints have their origin in three operational logics: the Emitter's Logic, the Recipient's Logic and the Distribution's Logic. The conflicts between those logics have been identified, which interfere with the operations and physical limits of the assembler. This research introduced a new perspective o CKD system analysis.

Keywords: CKD system. Supply chain. Operational logics. Strategy. Auto industry.

\section{INTRODUÇÃO}

Para crescer no mercado e obter economia de escala é preciso pensar a logística de forma globalizada, não se atendo somente a estratégias regionais (BOWERSOX; CLOSS, 2009). Na indústria automobilística são quatro as

\footnotetext{
${ }^{1}$ Texto inédito, resultado de dissertação de mestrado de Freitas (2015).
} 
possibilidades de internacionalização da produção, que vai desde a importação dos carros já montados até a produção totalmente estabelecida no mercado local (MEZNAR, 2012; TULDER; RUIGROK, 1997). O presente estudo foi direcionado à análise de uma cadeia de suprimentos que utiliza uma estratégia intermediária a esses dois extremos, chamada de estratégia de produção Completely Knoked Down (CKD).

A motivação deste trabalho surgiu de um projeto logístico, demandado por uma montadora nacional, operando em regime CKD, que vivenciava problemas causados pela falta de uma lógica eficiente de ocupação de seus armazéns pelos componentes importados e, também, pelo manuseio desses componentes no decorrer dos processos de recebimento, armazenamento e abastecimento das linhas de montagem. Os carregamentos, descarregamentos e traslados das peças entre as Unidades Produtivas da fábrica (UPs) exigiam elevada quantidade de recursos e aumentavam a frequência de peças danificadas.

Foi identificado que a montadora estava inserida em um ambiente com diferentes lógicas de operação, provenientes de seu fornecedor (exportador dos kits de componentes) e do próprio sistema de abastecimento das linhas de montagem. Essas lógicas traziam condicionantes que influenciavam diretamente 0 gerenciamento das operações logísticas da montadora em determinadas etapas.

A partir da identificação do problema real, não foram encontradas na literatura nacional ou internacional, abordagens que fizessem referência às condicionantes produtivas existentes nesse tipo de estratégia de produção e como estas poderiam afetar as operações de uma montadora.

Neste contexto, esse artigo apresenta e discute quais são as condicionantes que uma cadeia de suprimentos, operando num sistema CKD, produz sobre as operações produtivas de uma montadora automobilística.

Nas seções seguintes, apresenta-se o método de pesquisa utilizado na coleta dos dados. Depois é resumido um levantamento teórico sobre gerenciamento de cadeias de suprimentos e estratégia de operação CKD. Na sequência, é descrito o caso estudado e discutidas as lógicas operacionais encontradas ao longo das operações da montadora CKD. Encerra-se o trabalho com algumas considerações finais, que incluem as contribuições e limitações da pesquisa ora realizada. 


\section{REFERENCIAL TEÓRICO}

\subsection{Gerenciamento da cadeia de suprimentos}

Segundo VOLLMANN et al. (2006), o gerenciamento de cadeias de suprimentos tem como objetivo coordenar os fluxos de informações e materiais ao longo das empresas, "reconhecendo que as principais melhorias acontecem na coordenação global". Isso quer dizer que, as empresas têm ampliado seus esforços gerenciais na integração interfirmas, e não somente intrafirmas (GOMES; KLIEMANN, 2015), em uma tentativa de melhorar o desempenho competitivo de longo prazo (CASTRO et al., 2015). Isso é possível racionalizando o número de fornecedores para alcançar estoques menores, baixos custos, menores leadtimes de produção e, consequentemente, menores tempos de resposta ao mercado (VIANA; BARROS NETO; AÑEZ, 2014; CHEN; PAULRAJ, 2004; VOLLMANN et al., 2006).

Para lograr esses resultados, os elos da cadeia de produção devem estabelecer acordos de longo prazo (GUIMARÃES et al., 2014), operar com mínimo estoque e compartilhar um sistema de comunicação que possibilite a sincronização de ações e a transferência de conhecimentos, de modo a gerar soluções rápidas para os problemas e imprevistos eventuais (VOLLMANN et al., 2006; FERREIRA; LI; SERRA, 2010). A partir disso, verifica-se que o foco muda de uma "produção enxuta" clássica para uma "cadeia de suprimentos enxuta" (HINES; HOLWEG; RICH, 2004; VOLLMANN et al., 2006; BUSANELO, 2014).

Particularmente na indústria automobilística, o Brasil é objeto de experimentações de arranjos organizacionais que atribuem a determinados tipos de fornecedores um novo papel de dirigir a modularidade (VANALLE; SALLES, 2011). Após os anos 90, as fábricas foram sendo construídas com maior participação dos fornecedores externos, nos chamados condomínios industriais e consórcios modulares, onde os fornecedores estabeleciam suas instalações nas intermediações da montadora e passavam a fornecer subconjuntos completos just-in-sequence diretamente na linha de montagem (GUARNIERI; HATAKEYAMA; RESENDE, 2009; VANALLE; SALLES, 2011). Esses tipos de arranjos corporativos foram exemplificados nos trabalhos de Santos e Gonçalves (2015) e Carnevalli et al. (2015). 
Tendências em globalização, customização em massa e e-business incentivam as companhias de manufatura a perseguirem redes de produçãodistribuição globais para ganhos de vantagens competitivas (CHOI; NARASIMHAN; $\mathrm{KIM}$, 2012) como economia de escala e de comercialização (BOWERSOX; CLOSS, 2009). Honório e Rodrigues (2006) realizaram uma survey com 73 exportadoras brasileiras e concluíram que o processo de motivação internacional dessas exportadoras era decorrente da oportunidade de lucro e do crescimento no mercado internacional, da necessidade de reduzir a dependência dos riscos do mercado doméstico e dos interesses e crenças gerenciais em relação a atividades internacionais.

Além disso, Lee, Abosag e Jooyoung (2012) explicam que as parcerias e o comprometimento de recursos entre as multinacionais e empresas locais permitem à empresa estrangeira aprender mais sobre os usuários, fornecedores, clientes e concorrentes locais, e sobre o ambiente institucional. Vanalle e Salles (2011) e Castro et al. (2015) acrescentam que a integração interfirmas permite também o aprendizado interorganizacional, a transferência de tecnologia e a junção de competências, além de conferir para essas parcerias papeis fundamentais na minimização de risco de comportamentos oportunistas entre os parceiros.

É importante salientar que, apesar de existir na teoria uma utópica relação de ganha-ganha entre os elos da cadeia de suprimentos, analisando integrações de organizações automobilísticas nota-se que nem todas as empresas integrantes de uma cadeia possuem igual poder de decisão e controle, alinhamento estratégico, repartição equivalente dos ganhos e acesso a recursos e informações iguais (ALVES et al., 2004; GOMES; KLIEMANN, 2015).

Mesmo assim, as empresas tendem a fragmentar seus negócios (ADALBA, 2011), buscando mercados estratégicos em diferentes lugares e, desse modo, se deparam com grandes mudanças comportamentais, estruturais e econômicas entre o país de origem e o país hospedeiro (CHOI et al., 2012; ROCHA; ÁVILA, 2015). Essas divergências podem funcionar como barreiras de entrada e como fontes de prejuízo, e, por isso, as companhias prospectam sua entrada no mercado global escolhendo o local das novas instalações e decidindo qual estratégia internacional adotar por meio de uma análise rigorosa do ambiente externo, do uso de planos 
formais detalhados, da avaliação contínua do processo de implementação e da utilização de competências na escolha da estratégia (HONÓRIO, 2009).

Uma dessas estratégias de internacionalização, ou também chamada de estratégia de postponement por Choi et al. (2012), é a exportação de kits Completely Knocked Down (CKD).

\subsection{Completely Knocked Down}

A CKD é uma das formas possíveis de transferência de tecnologia e entrega de produtos entre países e está inserida em uma das quatro estratégias específicas de internacionalização da indústria automobilística (MEZNAR, 2012). Essas quatro estratégias, expostas em ordem crescente ao uso do conteúdo local, são: exportação de carros acabados (Completely Built-up - CBU), exportação e montagem local de carros parcialmente desmontados (Semi Knocked-Down - SKD), exportação e montagem local (no país onde os automóveis serão vendidos) de produtos totalmente desmontados (CKD) e fabricação local integralizada (TULDER; RUIGROK, 1997).

As duas primeiras estratégias têm como objetivo servir o mercado local deixando o complexo de carros nacional relativamente intocável. As duas últimas estratégias funcionam às vezes como divisão internacional do trabalho e podem servir como primeira etapa para a nacionalização dos produtos estrangeiros, quando o intuito final é estabilizar relações de negócios no novo mercado ( $\mathrm{CHOl}$ et al., 2012; SCAVARDA; HAMACHER, 2010; TULDER; RUIGROK, 1997). Um exemplo desse caráter transitório do CKD pode ser visto em Simpson, Skykes e Abdullah (1997) e Kim (1998).

Além de evitar custos de importação com produtos $\mathrm{CBU}$, as estratégias Knocked-Down exigem investimentos em tecnologia, infraestrutura, mão-de-obra e desenvolvimento de fornecedores nos países emergentes (KLUG, 2010; LIMA, 2015), gerando oportunidades de negócio e de emprego no país alvo ( $\mathrm{CHOl}$ et al., 2012).

Uma montadora CKD é útil para evitar barreiras comerciais para produtos CBU sob o protecionismo do comércio internacional. Plantas SKD/CKD são menos dispendiosas para construir e se manter, porque não precisam automações 
modernas, e o custo da mão-de-obra é geralmente menor em comparação ao país de origem. Elas também são eficazes para produção em pequena escala. A estratégia CKD permite que as empresas em mercados em desenvolvimento ganhem experiência em uma determinada indústria. Ao mesmo tempo, a empresa exportadora do kit CKD ganha acesso a novos mercados, inacessíveis de outra maneira, e conhece suas culturas (CHOI et al., 2012; KLUG, 2010).

Por outro lado, Guimarães (2013) acredita que a principal desvantagem da exportação CKD é o tempo de transporte dos materiais entre regiões distantes, em ambiente corrosivo, quando transportados por navios.

Não foram encontrados na literatura artigos que promovessem o CKD como condicionantes de processos produtivos, com exceção de alguns trabalhos acadêmicos da Universidade do Porto (FEVEREIRO, 2012; GUIMARÃES, 2013) e da Universidade de Aveiro (SILVA, 2008; COSTA, 2009; CORREIA, 2011), em Portugal. Esses trabalhos mapearam os fluxos de valor do processo produtivo de famílias de produtos de uma montadora automobilística portuguesa, alimentada por kits CKD proveniente do grupo Toyota do Japão, identificando os seguintes problemas:

- grandes inventários, devido a quantidade de kits CKD encomendados;

- disparidade de tempo de ciclos nos vários processos causando descontinuidade do fluxo de produção, filas de espera e perdas de qualidade;

- abastecimentos internos realizados em lotes condicionados à forma como as peças CKD vinham do Japão. Essa situação gerava estoques de veículos, contrapondo a política do sistema puxado de produção utilizado pelo seu fornecedor japonês;

- atrasos no abastecimento das linhas de montagem.

Os autores desses trabalhos propuseram a implementação de um sistema com lotes unitários, abastecidos por trens para flexibilizar a produção. Essa proposta demandou esforços por parte da montadora e por parte do fornecedor dos kits CKD.

\section{MÉTODO DE PESQUISA}

Foi conduzida uma pesquisa qualitativa e quantitativa, tendo como universo de estudo a montadora e o fornecedor CKD. O estudo quantitativo (simulações) deu 
suporte aos dados encontrados no qualitativo, agregando valor às análises (BRYMAN, 2007). Como o objetivo proposto é ainda pouco investigado, este artigo tem caráter exploratório (VOSS; TSIKRIKTSIS; FROHLICH, 2002).

O método utilizado foi o estudo de caso, que contempla abordagens amplas através de estudos empíricos que investigam fenômenos atuais no contexto de vida real, baseando-se na coleta de dados de múltiplas fontes de evidências (VOSS; TSIKRIKTSIS; FROHLICH, 2002; YIN, 2005; MIGUEL, 2012). Voss, Tsikriktsis e Frohlich (2002) defendem que esse método é considerado um dos melhores para a área de Operations Management, principalmente para o desenvolvimento de novas teorias.

O fenômeno investigado foi o conflito de lógicas emergentes do sistema de produção CKD dentro do contexto da cadeia de suprimento da montadora estudada. O escopo deste estudo foi um recorte dessa cadeia, onde foram investigadas as transações de materiais e informações entre o fornecedor CKD e a montadora nacional, e os processos logísticos internos da planta até a liberação dos veículos finalizados para a distribuição nas concessionárias.

Os dados são provenientes de ações desenvolvidas em um projeto de logística realizado em uma montadora automobilística CKD pelo Grupo de Pesquisa e Extensão SimuCad do Departamento de Engenharia de Produção (DEP) da Universidade Federal de São Carlos (UFSCar).

Definida uma estrutura conceitual/teórica, de forma a colher proposições que direcionassem as ações dos pesquisadores no caso prático (MIGUEL, 2012), foram identificadas lacunas que pudessem justificar a pesquisa, decorrente da escassez de trabalhos acadêmicos sobre a estratégia de produção CKD. A coleta de dados foi baseada em documentos de projeto, observações diretas, registros em diário de campo, anotações, fotografias, filmagens e entrevistas não estruturadas com diferentes atores. Essa variedade de dados provenientes de diferentes fontes é necessária para haver a triangulação das informações e aumentar a validade dos resultados (VOSS; TSIKRIKTSIS; FROHLICH, 2002; YIN, 2005; MIGUEL, 2012).

Em relação aos documentos de projeto, desenvolveu-se uma investigação dos processos operacionais da fábrica que resultou em arquivos de dados, resultados e relatórios. Esses documentos foram essenciais para o primeiro entendimento dos processos da fábrica e serviu como base de dados para esta 
pesquisa, sendo extraídas deles as condicionantes operacionais que afetavam a montadora. Os documentos disponibilizados foram:

- contrato entre as equipes de projeto (SimuCad e montadora): seu conteúdo revelou o problema principal da fábrica, a falta de uma organização sistemática na logística de chegada de materiais. Esse documento foi importante para entender quais eram as dificuldades sofridas pela empresa e seu contexto organizacional;

- relatórios técnicos contendo a descrição detalhada dos produtos resultantes do projeto. Neles foram gerados mapas-fluxogramas no nível de block-layout, representando os fluxos de materiais e de informações entre as UPs da montadora nos processos de chegada de materiais, abastecimento da produção, liberação de produtos acabados e outras saídas. Além disso, foram detalhados o processo de blocagem e o de armazenamento dos itens, foi identificado o mix de produção e foram realizadas análises dos tempos de chegada dos pedidos CKD, da formação de embarques na fornecedora e da composição da carga dos cases (caixas), dos contêineres e dos navios;

- listas de atribuição de tarefas prescritivas e de componentes e peças de montagem dos veículos, chamadas de job allotment, para cada estação da linha de montagem. Os job allotments foram importantes na confrontação entre 0 trabalho prescrito e 0 trabalho real dos trabalhadores. A diferença encontrada entre eles interferia o trabalho da logística, uma vez que o destino das peças era alterado conforme era modificada a ordem das tarefas nas estações da linha de montagem. Logo, na pesquisa de campo, esses documentos constantemente desatualizados foram percebidos como uma das causas dos manuseios desnecessários das peças;

- manual de logística operacional disponibilizado para o treinamento dos trabalhadores da montadora. Esse manual apresentou o fluxo de peças CKD até a sua chegada à montadora.

As observações diretas foram realizadas em visitas técnicas à montadora, no período de janeiro de 2013 a abril de 2014, permitindo a familiaridade dos 
pesquisadores com o caso, a confrontação entre a realidade e o que foi registrado nos arquivos e documentos, e a vivência da cultura organizacional da fábrica.

Durante as visitas de campo, os autores registraram anotações em diários de campo das suas perspectivas sobre as situações ocorridas na montadora, principalmente sobre as impressões observadas e feedbacks das reuniões realizadas com o corpo técnico-administrativo (diretores, gestores e analistas) da fábrica e, também, historiaram as implicações que eventos inesperados traziam para as atividades logísticas. Através de fotos, filmagens e anotações das operações rotineiras foram registrados os procedimentos logísticos e produtivos da planta, dos armazéns e das estações produtivas. Estes registros garantiram a preservação da memória das observações diretas das visitas técnicas.

Foram realizadas entrevistas informais com os profissionais, entre eles, gerentes, analistas e operadores, durante as visitas de campo, de modo a capturar suas percepções sobre os processos logísticos e de produção da fábrica.

\section{ESTUDO DE CASO}

O estudo de caso foi realizado em uma montadora automobilística pertencente a uma holding brasileira com 40 anos de experiência no mercado automotivo. Essa montadora foi inaugurada em 2007 para montar exclusivamente automóveis importados completamente desmontados (CKD) de uma montadora multinacional sul-coreana. Desse modo, o suprimento da fábrica era feito $90 \%$ por peças CKD e o restante por módulos provenientes de fornecedores nacionais e chineses.

A parceira estrangeira sul-coreana era, então, o fornecedor principal da montadora e responsável pela consolidação e envio de embarques contendo pedidos dos kits CKD dos automóveis. A montadora brasileira era responsável por realizar a montagem integral dos veículos, realizando as armações das carrocerias, as pinturas estruturais e das peças e os acabamentos finais.

Em 2013, a produção mensal dessa fábrica foi de 5700 veículos, caracterizando-a como uma montadora pequena/média e pouco automatizada quando comparada a seus pares. Nesse período, o mix de produção era constituído de três modelos de automóveis: dois Sport Utility Vehicle (SUV), chamados aqui de 
SX e SN, que compartilhavam a mesma linha de montagem; e, uma caminhonete, chamada de CR.

Dada a distância geográfica entre a produção de itens CKD, originados da Coreia do Sul, e a produção de veículos no Brasil, o sistema logístico entre esses dois eventos abrangia os macroprocessos apresentados na Figura 1.

Figura 1 - Macroprocessos Logísticos

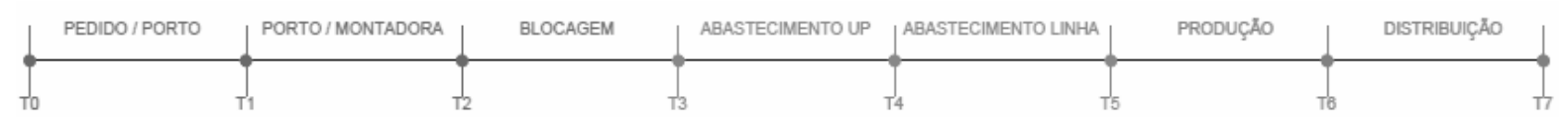

Fonte: FREITAS (2015)

O macroprocesso T0/T1 envolvia operações relacionadas a emissão dos pedidos de peças/componentes pela montadora para o fornecedor CKD até a chegada dessas ao porto no Brasil. O T1/T2 referia-se aos processos alfandegários sofridos pela mercadoria CKD nos portos brasileiros. O T2/T3 compreendia 0 recebimento dos contêineres carregados de peças no pátio da montadora até o arranjo desses pedidos nos armazéns da planta e suas consequentes liberações para a linha de montagem. O T3/T4 contemplava o abastecimento das UPs da fábrica. O T4/T5 envolvia o abastecimento das estações produtivas das linhas de montagem. O T5/T6 correspondia aos processos de produção dos carros. Por fim, o T6/T7 representava a distribuição dos automóveis na rede de concessionárias. Cada um desses processos é detalhado nas seções seguintes.

\subsection{Processo à montante da montadora: Processos T0-T1 e T1-T2}

\subsubsection{Processo TO-T1}

A companhia sul-coreana enviava peças e módulos desmontados CKD de seus veículos para montadoras localizadas em diversas partes do mundo, como estratégia de internacionalização de seus negócios.

O processo era iniciado a partir do momento que o fornecedor CKD recebia as ordens de pedidos de suas parceiras (montadoras). De acordo com as ordens, ele terceirizava e comprava as peças/componentes de fornecedores subcontratados (nível 2) e, segundo uma lógica genérica de empacotamento, embalava os pedidos e 
os transportavam em contêineres até o embarque em navios para os países de destinos.

Cada pedido enviado à montadora brasileira continha peças para a montagem de 300 carros de um determinado modelo. Entretanto, a Composição da Carga dos Navios (CCN) não seguia uma regularidade de pedidos, pois um mesmo pedido era comumente fracionado e enviado em diferentes viagens de navios para 0 Brasil. De acordo com dados empíricos, um pedido completo chegava ao porto brasileiro aproximadamente em 3 navios, atrasando o tempo de chegada dos contêineres desse pedido na montadora em pelo menos 14 dias, dado que o intervalo entre as saídas dos navios da Coreia do Sul para o Brasil era de 7 dias.

\subsubsection{Processo T1-T2}

Desembarcados os contêineres no porto, estes passavam por processos alfandegários e eram liberados para a montadora. Nesses processos, 1\% dos contêineres era geralmente direcionado ao canal vermelho da receita federal, onde ocorria a conferência documental e a fiscalização das mercadorias, enquanto o restante passava direto, sem qualquer verificação.

Dessa dinâmica, eram gerados três tempos de processamento. O primeiro, Tempo de Liberação no Porto (TLP), correspondia ao tempo decorrido durante a liberação dos contêineres no porto para irem em direção ao Porto Seco, localizado próximo à montadora. Estimar esse tempo com precisão era impossível, uma vez que podia variar entre 2 e 26 dias. Do porto, as cargas levavam 1 dia para chegar ao porto seco. Uma vez no porto seco, gerava-se o Tempo de Liberação no Porto Seco (TLPS), que podia variar entre 0 e 49 dias. As variações foram baseadas na análise de 599 registros dos TLP e TLPS em 2012.

\subsection{Processos dentro da montadora: Processos T2-T3, T3-T4, T4-T5 e T5-T6}

\subsubsection{Processo T2-T3}

Liberados dos processos alfandegários, os contêineres eram encaminhados para a montadora, onde eram recebidos no pátio para posterior armazenamento de 
seus cases. Existiam dois armazéns (WHs) na montadora, um para os cases que continham peças predominantemente consumidas na Unidade Produtiva (UP) BODY e outro WH para os cases contendo peças consumidas nas UP TRIM e UP PAINT (cada UP será depois explicada).

O processo de blocagem era iniciado após o descarregamento dos contêineres no pátio, quando todos os cases contidos neles passavam por um processo de inspeção de qualidade. Desta consideração, surgiam duas alternativas:

- $\quad$ se as peças inspecionadas estivessem dentro do padrão de qualidade, o case era liberado para ser armazenado. Mas o armazenamento era condicionado à existência de outro case do mesmo pedido alocado no armazém correspondente. Se já existisse outro case alocado em uma vaga, então o case inspecionado se juntaria ao bloco de seu pedido. Caso contrário, ele esperaria no pátio até que existisse uma vaga disponível no armazém;

- se peças do case estivessem sem conformidade, era gerado um pedido de reposição ao fornecedor, ficando o pedido correspondente (em processo de blocagem) retido até o recebimento dessas peças. Podia ocorrer uma solicitação de recuperação da peça que, caso resultasse em sucesso, o case era liberado para completar o pedido correspondente. Caso contrário, o material era descartado e um pedido de reposição era gerado.

Os cases eram armazenados nos WHs correspondentes. Mas eles podiam conter peças de mais de uma UP. Portanto, era frequente o intercâmbio de peças entre os dois armazéns.

Assim, a alocação dos pedidos nos armazéns funcionava de acordo com o número de posições (vagas) de armazenamento para cada modelo de veículos.

\subsubsection{Processos T3-T4 e T4-T5}

As UPs da montadora eram o BODY, que soldava a parte estrutural dos automóveis; o PAINT, responsável pela pintura das peças; e o TRIM, responsável pelo acabamento final dos carros. 
Quando um pedido era blocado completo em sua vaga nos armazéns e liberado para ser consumido, seus cases eram classificados, de acordo com as características de seus itens, em:

- direto, se seus itens fossem volumosos e levados para a linha de produção em seus cases (embalagens) originais;

- manuseio, se seus itens precisassem de manipulação antes do processo de abastecimento das linhas de produção;

- $\quad$ separação, se continham itens destinados para mais de uma UP e/ou estação das linhas de produção.

Ainda, em cada pedido, os itens Separação podiam vir organizados nos cases em lotes denominados "comuns", contendo peças do tipo pequenas ou médias para a montagem de 30 carros, ou em lotes únicos nomeados "iniciais", contendo peças do tipo miudezas (porcas, parafusos, adesivos, etc) necessárias em várias etapas da montagem dos 300 veículos do pedido relacionado. Os lotes "iniciais" vinham distribuídos em 100 cases por pedido e ficavam abertos no armazém desde a montagem do primeiro até o último carro associado àquele pedido.

Após a classificação (e de acordo com ela), os materiais seguiam para as UPs e, depois, para as estações dos sidelines de modos diferentes. Os itens diretos eram transportados por empilhadeiras; já os itens menores, por carrinhos manuais. Para itens "separação" era realizada mais uma etapa de reclassificação e de fracionamento de itens. Os itens de manuseio e de separação eram dispostos em dispositivos modulares nos sidelines, que comportavam peças para mais de um modelo (quando linha compartilhada). E assim por diante.

Vê-se, portanto, a multiplicidade e heterogeneidade do abastecimento de peças/componentes nas linhas de montagem.

\subsubsection{Processo T5-T6}

Os três subsistemas, Montagem Estrutural (BODY), Pintura (PAINT) e Montagem Final (TRIM), operavam de forma independente segundo suas diferentes capacidades, necessitando de buffers para intermediar a produtividade de cada etapa. O BODY possuía quatro linhas de produção (uma para o SX, uma para o SN e duas para o CR) com capacidades fixas e distintas entre si. O PAINT possuía uma 
linha com capacidade fixa compartilhada entre todos os modelos. No TRIM existia uma linha de montagem compartilhada pelos SX e SN, com capacidade fixa distribuída em proporção flutuante entre os dois modelos e suas três cores; e uma linha exclusiva para o $\mathrm{CR}$, com capacidade fixa para uma cor única.

$\mathrm{Na}$ linha de montagem compartilhada no TRIM as taxas de produção eram diferenciadas para os dois modelos de carros e um mesmo dispositivo no sideline comportava peças dos dois veículos e em diferentes quantidades. Além disso, os trabalhadores dessa linha alteravam frequentemente a ordem das operações de montagem entre as estações produtivas na busca do aumento da eficiência produtiva local.

\subsection{Processos à jusante da montadora: Processos T6-T7}

O processo de distribuição dos carros montados pela montadora sofria com a natureza do mercado automotivo volátil, típico do setor. Suas vendas dependiam tanto da aceitabilidade dos consumidores pelos atributos do produto, quanto de ações políticas e econômicas do país, dos valores das taxas de impostos, da concorrência e da disponibilidade de crédito ao consumidor.

Entretanto, existia um fator a mais que influenciava na distribuição e, consequentemente, na produção desses carros. A distribuição era condicionada às decisões tomadas pela holding, que controlava a montadora, em função de suas prioridades estratégicas de negócios, uma vez que os produtos provenientes da montadora competiam diretamente com a venda de carros multimarcas e com a importação de produtos CBU, que também faziam parte dos negócios da holding.

\section{AS LÓGICAS OPERACIONAIS CONDICIONANTES}

Por meio da análise dos macroprocessos dessa cadeia de produção, observou-se a presença da influência de três lógicas operacionais que condicionavam a produção da montadora, envolvendo os macroprocessos logísticos (Figura 2). 
Figura 2 - Lógicas Operacionais das Operações da Montadora

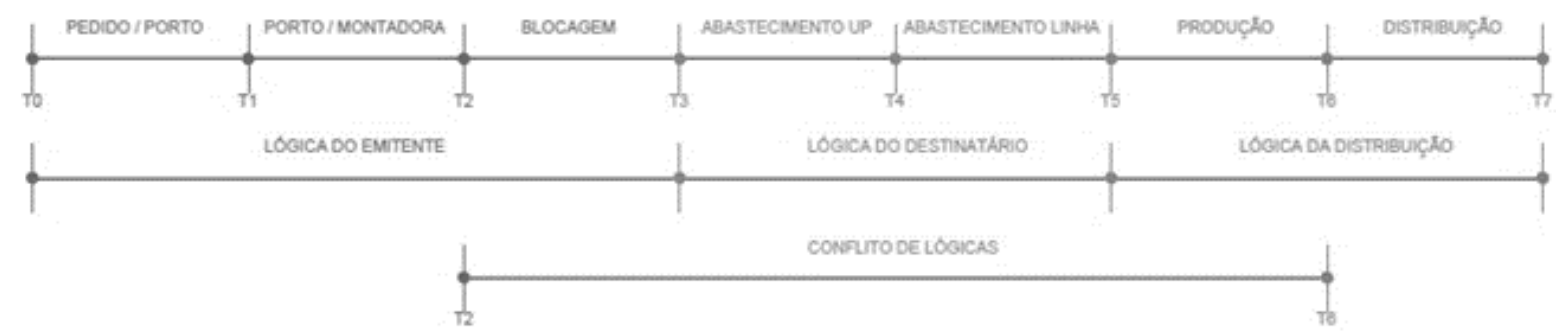

Fonte: FREITAS (2015)

A primeira lógica operacional observada foi a do fornecedor CKD, Lógica do Emitente, que condicionava os processos presentes entre T0 e T3. A segunda lógica, Lógica do Destinatário, emergiu da montadora para abastecer suas UPs e linhas de montagem. E, por fim, a última lógica, Lógica da Distribuição, proveniente da holding brasileira, intervinha na produção e na distribuição dos carros.

Essas lógicas eram confrontadas dentro dos limites físicos da montadora, revelando-se assim um conflito de lógicas e gerando uma necessidade de esforços gerenciais para dar fluidez ao processo produtivo da montadora CKD. Nas próximas seções são detalhadas cada uma delas.

\subsection{Lógica do Emitente}

A montadora foi criada com a única finalidade de montar kits CKD de uma empresa multinacional sul-coreana. $O$ fato de envolver somente um fornecedor relevante de primeiro nível e de existir um contrato de longo prazo entre cliente e fornecedor, não foi suficiente para dar a essa cadeia as vantagens de baixos estoques e seus desdobramentos como aventava VOLLMANN et al. (2006). Também não foi encontrada nessa cadeia a preocupação de um gerenciamento global, não se enquadrando como uma "cadeia de suprimento enxuta" (HINES et al., 2004; VOLLMANN et al., 2006; BUSANELO, 2014). A prova disso era a existência de variabilidades na Composição da Carga dos Navios (CCN) e na configuração das cargas dos cases que chegavam à montadora. Talvez isso acontecesse porque a montadora brasileira não era uma filial da empresa sul-coreana e, por isso, os interesses de ambas conflitavam entre si.

Nos processos T0-T3 existiam também as variabilidades temporais de chegada dos contêineres dos pedidos na montadora, já citadas nos estudos 
portugueses (SILVA, 2008; COSTA, 2009; CORREIA, 2011; FEVEREIRO, 2012; GUIMARÃES, 2013), não só por causa dos fretes de longas distâncias, mas também por conta dos processos alfandegários. Além disso, a presença frequente de peças rejeitadas pela montadora e de peças danificadas ao longo dos manuseios nas operações podia representar um sinal de baixo esforço por parte das empresas para implementar programas de qualidade, mencionado por VOLLMANN et al. (2006). As peças sem conformidades eram transtornos para o processo de blocagem (T2-T3), pois impediam essa operação do pedido correspondente até a peça ser consertada ou até o recebimento de uma nova.

Essas variabilidades determinavam, então, o tempo de formação dos pedidos (blocagem de pedidos completos) nos armazéns da montadora (Tabela 1). Esse tempo era de aproximadamente 48,70 e 62 dias para os modelos CR, SN e SX, respectivamente, em um contexto contendo anomalias nos processos de entrega de material. Esses tempos passavam a ser de aproximadamente 27, 42 e 40 dias numa situação sem anomalias ao longo do transporte.

Tabela 1 - Tempos de formação de pedidos

\begin{tabular}{ccccccccccccc}
\cline { 2 - 10 } & \multicolumn{4}{c}{ Navio Atual } & \multicolumn{4}{c}{ Navio Ideal } \\
\cline { 2 - 11 } & \multicolumn{1}{c}{ Com Anomalia } & Sem Anomalia & \multicolumn{4}{c}{ Com anomalia } & \multicolumn{3}{c}{ Sem Anomalia } \\
\hline Produto & CR & SN & SX & CR & SN & SX & CR & SN & SX & CR & SN & SX \\
\hline Tempo formação do primeiro pedido (dias) & 47,5 & 70,1 & 61,7 & 26,6 & 41,8 & 39,8 & 47,5 & 48,6 & 49,6 & 26,6 & 25,4 & 23,5 \\
\hline
\end{tabular}

Fonte: Adaptado de FREITAS (2015)

Na mesma tabela visualiza-se também os resultados de uma simulação com uma CCN ideal (navios transportando pedidos completos, sem dispersão de cargas). Nesse caso, todos os tempos de formação de pedidos do SN e do SX seriam consideravelmente reduzidos.

Considerando esses fatos, a lógica do emitente era composta por outras três lógicas:

- Lógica de Compactação de Cargas: a existência de contrato de médio/longo prazo estabelecido entre a montadora e o fornecedor único (CKD) determinava o fluxo de recebimento dos materiais. 0 empacotamento genérico caracterizava a falta de customização do empacotamento das cargas em função do destinatário. O envio de peças pelo fornecedor visava à compactação de cargas, que constituía uma 
dimensão da competitividade da produção CKD, pois reduzia os custos logísticos unitários de material transportado. Mas, por outro lado, condicionava as operações logísticas da montadora em termos de tempo, custos de processamento de carga e volume de armazenagem. Uma solução para esse problema seria se a $\mathrm{CCN}$ e o arranjo das cargas nos cases fossem feitos de acordo com as operações produtivas da montadora;

- Lógica de Custo de Transação: justificava o tamanho dos lotes dos pedidos (300 carros), visando a redução do custo de aquisição através da economia de escala;

- Lógica de Liberação de Mercadorias na Alfândega: a verificação da conformidade da mercadoria com a legislação estava fora do controle da montadora e contribuía com a variabilidade do tempo de formação de pedidos nos armazéns, uma vez que eram gerados tempos de operação flutuantes (TLP e TLPS).

\subsection{Lógica do destinatário}

Entre as operações de armazenamento dos cases (Blocagem) e de Abastecimento das UPs, existia uma conversão da Lógica do Emitente para a Lógica do Destinatário (destinatário aqui é referente a quem recebe os kits CKD, ou seja, a planta brasileira). Essa interface de lógicas distintas caracterizava os abastecimentos das UPs e das linhas de montagem como um processo complicado. Existia grande quantidade e variedade de peças para gerenciar e a forma como eram acondicionadas na origem (no fornecedor CKD) demandava grandes quantidades de manuseios no destino (montadora). Como consequência as operações logísticas necessitavam de um elevado número de trabalhadores. Tais variáveis complicavam o processo de abastecimento, mas, quando operadas dentro das conformidades esperadas, ou seja, sem eventos imprevisíveis, o abastecimento era assegurado e o sistema funcionava normalmente.

Entretanto, eventos inesperados, determinados pela presença de peças danificadas e rejeitadas, ocorriam e o fluxo normal de abastecimento era alterado. Isso tornava os sistemas de abastecimento complexos, porque a maioria dos itens 
não conformes que chegava à montadora era percebida somente na produção e os itens danificados pelo excesso de manipulação geravam a necessidade de reposição. Para não parar a produção, era realizada a operação chamada no chão de fábrica de "roubo".

Em função dos itens de reposição demandados pela produção, lotes completos eram adiantados para o abastecimento da produção. Dado que a reposição ("roubo") criava um desnivelamento na quantidade de peças nas estações, a ordem do abastecimento de linha era alterada, implicando que peças de um lote chegassem a estações de produção adiantadas antes de chegarem nas estações iniciais. Em um momento posterior, à montante do abastecimento de linha, um pedido de empréstimo era definido. Desse embarque eram retiradas as peças para substituir os itens de reposição e recompor os lotes enviados adiantadamente.

As reposições geravam desbalanceamentos no abastecimento das linhas. Se a reposição não era diretamente responsável pela falta de peças nos sidelines, ela introduzia uma turbulência no processo e certamente contribuía para a ineficiência dessas operações. O desbalanceamento propagava-se pelo processo de abastecimento, contaminando seu ritmo linear. Desse conjunto de condicionantes originava-se uma demanda alta de recursos pelos processos logísticos.

A lógica de ocupação dos armazéns da fábrica era fruto da fragmentação dos pedidos em diferentes viagens e de como as peças eram arranjadas nos cases. Se os navios transportassem pedidos completos (navios ideais), poderia ser reduzido o número de vagas nos armazéns, pois elas não ficariam congeladas recebendo pedidos por períodos longos. Logo, o estoque de materiais parados no pátio seria reduzido. Além disso, com o aumento da confiança do fornecimento de pedidos completos em tempos mais curtos, a quantidade de estoque diminuiria dos armazéns.

\subsection{Lógica da distribuição}

A cadeia de suprimentos analisada certamente não se enquadrava ao perfil da maioria das cadeias automobilísticas. Primeiro, devido à inadequação das operações CKD ao sistema de produção enxuta, predominante nestas cadeias. Segundo, porque o elo central da cadeia não era a montadora, como no caso dos 
condomínios industriais e consórcios modulares (GUARNIERI; HATAKEYAMA; RESENDE, 2009; VANALLE; SALLES, 2011).

A montadora estava inserida em um negócio mais amplo de distribuição de veículos multimarcas e não constituía o elo central do negócio. Essa empresa estava submetida à holding a qual pertencia e que, entre suas estratégias de operações e suas prioridades de vendas, determinava a quantidade de carros que iriam ser produzidos. Ou seja, a produção da montadora e sua distribuição estavam condicionadas a uma estratégia maior de distribuição, que tinha uma série de variáveis operacionais e estratégicas que não estavam contidas somente na operação de montagem.

Seguindo essa estratégia maior, a produção devia trabalhar em conjunto com o setor de logística para que o processo produtivo e a distribuição não falhassem. As questões principais de gerenciamento da produção buscavam estabelecer uma programação da produção, segundo a demanda estabelecida pela holding, que refletisse no balanceamento produtivo do sistema BODY/PAINT/TRIM. A questão principal da logística era garantir o suprimento de peças nas estações produtivas sem falta, com diferentes quantidades e frequência de abastecimento. Portanto, a logística arcava com a responsabilidade de calcular quando pedir peças ao fornecedor CKD, considerando o tempo de espera e anomalias inerentes ao sistema, preocupando-se com excessos e faltas que poderiam existir em função do tempo de resposta dado por essa montadora ao mercado.

Em um mercado com esse perfil, um curto tempo de resposta entre as flutuações da demanda e a produção dos carros pode se tornar uma vantagem competitiva. Na montadora estudada esse tempo de resposta era demorado e sofria muitas variabilidades em decorrências dos processos de importação CKD.

\subsection{Conflito de lógicas}

Entre o emitente (à montante) e a distribuição (à jusante) operava-se um sistema logístico que fazia a regulação entre a rigidez na entrada e a busca por uma flexibilidade na produção.

A existência de peças rejeitadas e danificadas por conta das operações, manuseios e transporte, geravam desbalanceamentos nas operações de 
abastecimento de linha. Operações de "roubos" de peças em outros lotes eram feitas e embarques ficavam congelados até serem novamente completados nos armazéns. Se a reposição não era responsável diretamente pela falta de peças na linha, ela iniciava uma turbulência no processo produtivo, contribuindo para a ineficiência das operações. Essa turbulência, gerada do desbalanceamento, contaminava todo o processo de abastecimento, de forma que coloca em xeque o fluxo linear de abastecimento.

Assim como ocorre com os outros materiais CKD, as reposições demandavam um tempo de espera de recebimento. Decorrente desse impasse e de outras eventualidades que podiam surgir no transporte desses materiais, cada etapa produtiva interna à fábrica poderia possuir uma categoria de fluxo de operações a ser organizada e gerenciada individualmente. Essa proposta foi esquematizada na Figura 3.

Figura 3 - Proposta de Regime de operação nas UPs

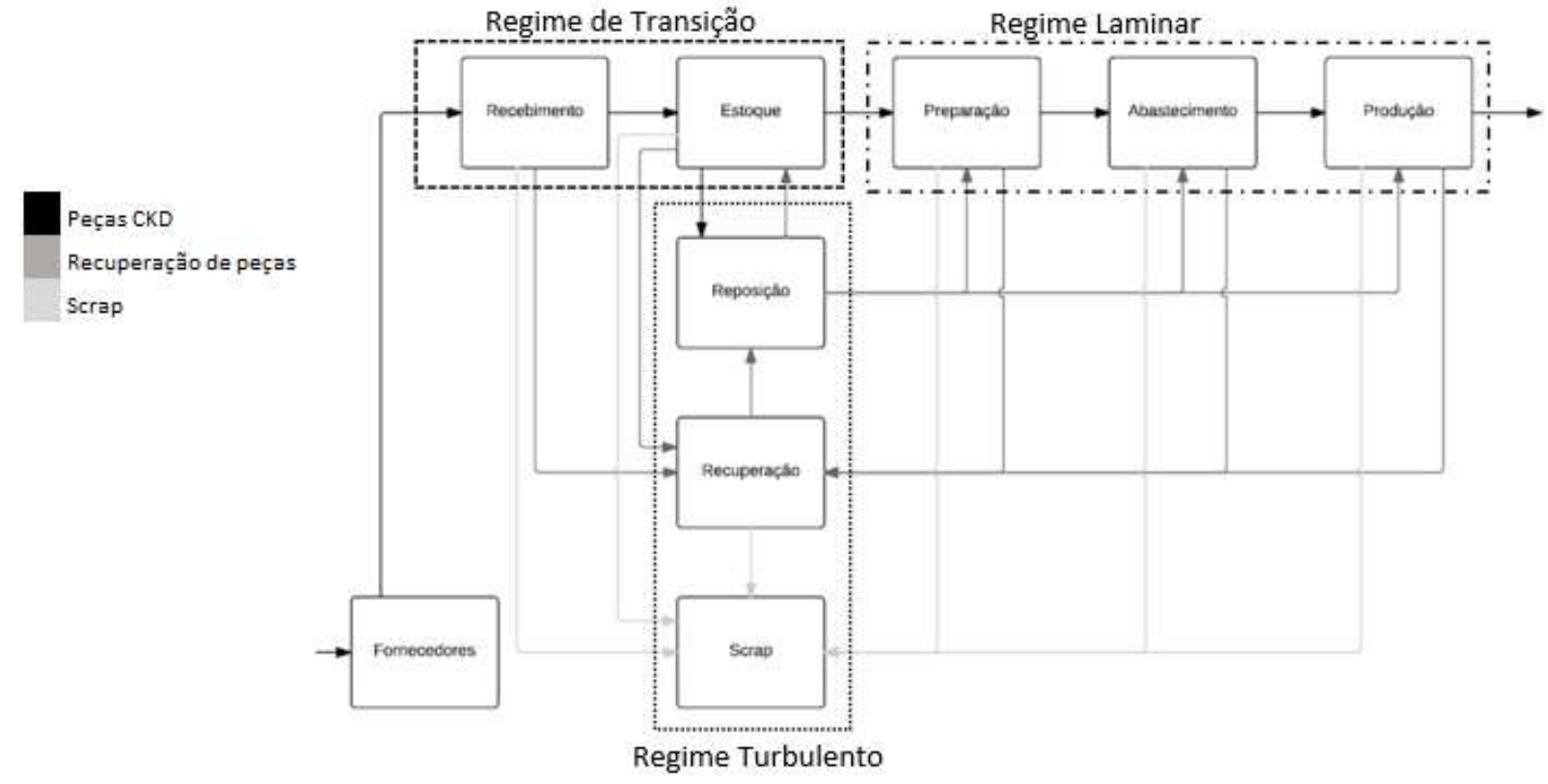

Fonte: Adaptado de Freitas (2015)

Cada regime de produção teria suas próprias características:

- regime turbulento: as operações de recuperação e reposição das peças aconteceriam quando surgissem peças rejeitas ou danificadas, cujo processo de abastecimento deveria ser realizado segundo essa demanda (não previsível) e de forma independente do abastecimento comum; 
- regime de transição: as operações à montante do abastecimento dos materiais nas UPs receberiam os itens CKD e de reposição, compondo os embarques completos para ser liberados. A função desses processos seria de absorver todas as variabilidades do regime turbulento, a fim de tornar possível o abastecimento das linhas de montagem em um processo laminar, ou seja, estável;

- regime laminar: as operações de preparação dos materiais, de abastecimento e de produção seriam realizadas sem interrupções, seguindo o plano de abastecimento pré-estabelecido. Esse plano seria subordinado à taxa de consumo das peças na produção. Uma nova redefinição do processo de abastecimento de linha seria necessária, substituindo o abastecimento das UPs em bloco por um processo de abastecimento nivelado pelo consumo das peças na produção.

Para facilitar o gerenciamento do regime de transição e atenuar os conflitos das lógicas emitente-destinatário, é preciso repensar na $\mathrm{CCN}$. O cenário atual prevê a manutenção da forma como os navios eram montados (primeiro quadro da Figura 4). Os pedidos eram distribuídos entre 2 e 4 viagens, impondo um acréscimo de tempo no recebimento dos pedidos de 7 a 21 dias. Em um cenário ideal, os pedidos estariam concentrados numa mesma viagem/navio e o impacto adicional seria nulo (segundo quadro da Figura 4).

Observa-se que a diferença é significativa. No cenário atual num período de 4 viagens, 9 pedidos estavam envolvidos. No cenário ideal, num mesmo período 4 pedidos estariam sendo manipulados.

Figura 4 - Proposta de Regime de operação nas UPs
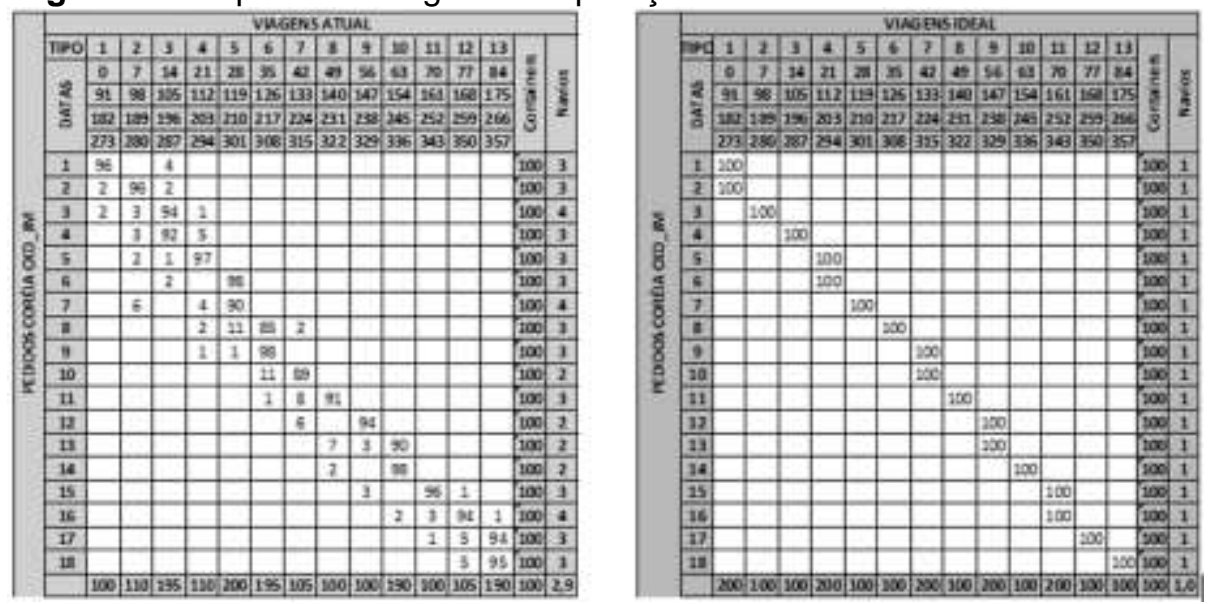

Fonte: Adaptado de FREITAS (2015)

Revista Produção Online. Florianópolis, SC, v.17, n. 4, p. 1454-1479, 2017. 
É sugerida então uma nova forma de reorganização dos embarques CKD da Coreia do Sul para o Brasil. Sabe-se que os pedidos de importação eram formados com peças equivalente a produção de 300 carros. Mas, o pedido vinha fracionado em vários navios ao Brasil. Portanto, havia um desnivelamento da chegada das peças na montadora, e as blocagens dessas nos armazéns ficavam em processo de espera durante todo o período de recebimento dos contêineres de um mesmo pedido. A proposta seria manter o tamanho de lote do pedido, porém arranjar esse grande lote em kits de peças CKD para a produção de 30 carros. Assim, cada navio que chegasse ao Brasil descarregaria kits completos para 30 carros, tornando 0 processo de blocagem na fábrica mais fluido e linear e mais próximo do "navio ideal".

\section{CONSIDERAÇÕES FINAIS}

Os benefícios econômicos e sócio-políticos defendidos por diversos autores (CASTRO et al., 2015; VANALLE; SALLES, 2011; CHOI et al., 2012; KLUG, 2010; LEE et al., 2012; MEZNAR, 2012) resultante das parcerias entre empresas, podem ser confirmados nessa pesquisa, uma vez que, após estabilizada a produção de carros CKD no Brasil, a fornecedora multinacional sul-coreana construiu uma montadora própria (filial) para a produção de um modelo de carro projetado exclusivamente para o mercado brasileiro. Além disso, essa informação traz a característica de regime transitório que tem a produção CKD defendida por (TULDER; RUIGROK, 1997; SCAVARDA; HAMACHER, 2010; CHOI et al., 2012; KLUG, 2010; MEZNAR, 2012).

O modelo de produção da montadora considerava a logística como uma variável de ajuste do sistema, subestimando suas potencialidades como uma dimensão estratégia. Desse modo, foi sugerido pelos autores um estado futuro para as operações na montadora (seção 5.4).

Esta pesquisa introduziu algumas noções que não foram encontradas nos trabalhos acadêmicos pesquisados (SILVA, 2008; COSTA, 2009; CORREIA, 2011; FEVEREIRO, 2012; GUIMARÃES, 2013). Primeiro a noção da existência da variabilidade da CCN, das cargas dos contêineres e dos cases. No caso da montadora estudada, essa variabilidade triplicava em média o tempo de espera da 
chegada dos contêineres de um mesmo embarque no porto, justificando assim sua importância junto às variáveis de distância entre os elos da cadeia, de tempo de processos alfandegários e de anomalias em geral.

Foi introduzida também uma nova perspectiva de análise de um sistema produtivo, identificando as lógicas operacionais condicionantes das operações de uma cadeia de suprimentos. Essa visão torna mais clara a origem dos problemas no caso de projetos de mudanças operacionais e melhorias de desempenho, trazendo contribuições sustentáveis para o ambiente produtivo. E, por fim, uma terceira noção apresentada foi a preocupação em enfatizar as peças rejeitadas e as peças danificadas ao longo das operações como causadores principais no desbalanceamento dos abastecimentos das linhas de montagem.

A limitação desse estudo foi intrínseca à característica de um estudo de caso único, isto é, não houve o estudo de outras montadoras semelhantes para reforçar a validação da generalização dos resultados obtidos nessa pesquisa. Considerando isso, propõe-se estudos posteriores de outras montadoras CKD. Seria interessante a análise de cadeias organizacionais que tenham parcerias entre um fornecedor CKD e uma montadora independente e parcerias entre o mesmo fornecedor CKD com uma montadora filial para permitir comparações das relações estabelecidas entre esses dois casos.

\section{REFERÊNCIAS}

ADALBA, M. R. Globalization, competition, and international production networks: policy directions for the Philippine automotive industry. PIDS Policy Notes 2011-13. Makati City: Philippine Institute for Development Studies, 2011.

ALVES FILHO, A. G.; CERRA, A. L.; MAIA, J. L.; SACOMANO NETO, M.; BONADIO, P. V. G. Pressupostos da gestão da cadeia de suprimentos: evidências de estudos sobre a indústria automobilística. Gestão \& Produção, v.11, n.3, p. 275-288, 2004.

http://dx.doi.org/10.1590/S0104-530X2004000300003

BOWERSOX, D. J.; CLOSS, D. J. Logística empresarial: o processo de integração da cadeia de suprimento. Atlas, 2009.

BRYMAN, A. Barriers to integrating quantitative and qualitative research. Journal of mixed methods research, v. 1, n. 1, p. 8-22, 2007. https://doi.org/10.1177/2345678906290531

BUSANELO, E. C. Cadeias de Suprimentos "Leagile" e a Geração de Valor. Organizações e Sustentabilidade, v. 2, n. 1, p.58-93, 2014. 
CARNEVALLI, J. A.; SOUZA, J. E. R.; BENEDICTO, S. C.; SALERNO, M. S.; MIGUEL, P. A. C. Modularidade em montadoras de automóveis: uma análise sob a ótica da estratégia. Revista Produção Online, v. 15, n. 2, p. 433-457, 2015. http://dx.doi.org/10.14488/1676-1901.v15i2.1741

CASTRO, M. R.; BRONZO, M.; RESENDE, P. T. V.; OLIVEIRA, M. P. V. Relacionamentos colaborativos e desempenho competitivo de empresas brasileiras. RAE, v. 55, n.3, p.314328, 2015. http://dx.doi.org/10.1590/S0034-759020150307

CHEN, I. J.; PAULRAJ, A. Towards a theory of supply chain management: the constructs and measurements. Journal of Operations Management, v.22, n.2, p.119-150, 2004. http://dx.doi.org/10.1016/j.jom.2003.12.007

CHOI, K.; NARASIMHA, R.; KIM, S. W. Postponement strategy for international transfer of products in a global supply chain: A system dynamics examination. Journal of Operations Management, v.30, n.3, p.167-179, 2012. http://dx.doi.org/10.1016/j.jom.2012.01.003 CORREIA, A. R. S. Optimização de uma linha de montagem final. 2011.70 p. Dissertação (Mestrado em Engenharia e Gestão Industrial), Departamento de Economia, Gestão e Engenharia Industrial - Universidade de Aveiro, 2011.

COSTA, A. M. G. Mapeamento do fluxo do processo na linha de montagem da Toyota Caetano para o modelo Dyna. 2009. 83 p. Dissertação (Mestrado em Engenharia e Gestão Industrial), Departamento de Economia, Gestão e Engenharia Industrial - Universidade de Aveiro, 2009.

FERREIRA, M. P.; LI, D.; SERRA, F. A. R. Transferência internacional de conhecimento na multinacional: quando o jogo competitivo multimercado se sobrepõe aos mecanismos internos de coordenação. RAE, v. 9, n. 1, 2010. http://dx.doi.org/10.1590/S167656482010000100002

FEVEREIRO, R. J. M. Definição de layout, fluxos de produção e capacidades de uma fábrica de produção de carroçarias na CaetanoBus, S.A. 2012. 59p. Dissertação (Mestrado em engenharia industrial e gestão), Faculdade de Engenharia da Universidade do Porto, 2012.

FREITAS, L. D. Organização da produção em uma montadora automobilística que opera em regime CKD: uma abordagem emitente-destinatário. 2015. 142f. Dissertação (Mestrado em engenharia de produção), UFSCar, 2015.

GOMES, L. C; KLIEMANN NETO, F. J. Métodos colaborativos na gestão de cadeias de suprimentos: desafios de implementação. RAE, v. 55, n. 5, p. 563-577, 2015. http://dx.doi.org/10.1590/S0034-759020150508

GUARNIERI, P.; HATAKEYAMA, K.; RESENDE, L. M. Estudo de caso de um condomínio industrial na indústria automobilística: caso GM Gravataí. Revista Produção Online, v. 9, n. 1, p. 48-72, 2009. http://dx.doi.org/10.14488/1676-1901.v9i1.199

GUIMARÃES, J. P. C. Concepção de linha de expedição de materiais CKD na CaetanoBus. 2013. 57p. Dissertação (Mestrado em engenharia industrial e gestão), Faculdade de Engenharia da Universidade do Porto, 2013.

GUIMARÃES, M. R. N.; TEODORO FILHO, A. M.; LARA, F. F.; SALTORATO, P. Estratégia de produção na indústria de autopeças: estudo multicasos em empresas da região de Sorocaba. Revista Produção Online, v. 14, n. 2, p. 499-532, 2014. 
http://dx.doi.org/10.14488/1676-1901.v14i2.1364

HINES, P.; HOLWEG, M.; RICH, N. Learning to evolve: a review of contemporary lean thinking. International Journal of Operations \& Production Management, v.24, n.10, p.994-1011, 2004. https://doi.org/10.1108/01443570410558049

HONÓRIO, L. C. Determinantes organizacionais e estratégicos do grau de internacionalização de empresas brasileiras. RAE, v. 49, n. 2, p. 162-175, 2009. http://dx.doi.org/10.1590/S0034-75902009000200004

HONÓRIO, L.; RODRIGUES, S. B. Aspectos motivacionais e estratégicos na internacionalização de empresas brasileiras. Revista de Administração de Empresas, v. 46, n. SPE, p. 86-98, 2006. http://dx.doi.org/10.1590/S0034-75902006000500007

KIM, L. Crisis construction and organizational learning: Capability building in catching-up at Hyundai Motor. Organization science, v. 9, n. 4, p. 506-521, 1998.

https://doi.org/10.1287/orsc.9.4.506

KLUG, F. Logistics implications of global production networks in car manufacturing. In:

Cambridge Symposium on International Manufacturing, 16., 2010, Cambridge: University of Cambridge, 2010.

LEE, J-W; ABOSAG, I.; JOOYOUNG, K. The role of networking and commitment in foreign market entry process: multinational corporations in the Chinese automobile industry.

International Business Review, v. 21, n.1, p. 27-39, 2012.

https://doi.org/10.1016/j.ibusrev.2011.10.002

LIMA, U. M. A dinâmica e o funcionamento da cadeia global de valor da indústria automobilística na economia mundial. Texto para Discussão, Instituto de Pesquisa Econômica Aplicada (IPEA), 2015.

MEZNAR, D. Transfer of Tehnology: Technical, Technological and Logistic Approach in the Production and Assembly Vehicles. Asian Journal of Business and Management Sciences, v. 1, n. 11, p 85-93, 2012.

MIGUEL, P. A. C; SOUZA R. O método do estudo de caso na engenharia de produção. In: MIGUEL, P. A. C. Metodologia de pesquisa em engenharia de produção e gestão de operações. Rio de Janeiro: Elsevier, 2012, p. 131-148.

ROCHA, A.; ÁVILA, H. A. Teoria institucional e modos de entrada de multinacionais de países emergentes. RAE, v. 55, n. 3, p. 246, 2015.

http://dx.doi.org/10.1590/S0034-759020150302

SANTOS, P. F. A. A.; GONÇALVES, C. A. Difusão de inovações entre organizações: evidências de um estudo na cadeia automobilística. RAI, v. 12, n. 3, p. 135-156, 2015. http://dx.doi.org/10.11606/rai.v12i3.101355

SCAVARDA, L. F. R.; HAMACHER, S. Evolução da Cadeia de Suprimentos da Indústria Automobilística no Brasil. Rio de Janeiro, RAC, v. 5, n. 2, p. 201-209, 2010. http://dx.doi.org/10.1590/S1415-65552001000200010

SILVA, R. M. P. Aplicação do Value Stream Mapping para o estudo e melhorias do processo produtivo. 2008. 86p. Dissertação (Mestrado em economia, gestão e engenharia industrial), Universidade de Aveiro, 2008. 
SIMPSON, M.; SYKES, G.; ABDULLAH, A. Transitory JIT at Proton Cars, Malaysia. Management Research News, v. 20, n. 2/3, p. 46-47, 1997. https://doi.org/10.1108/eb028539

TULDER, R.; RUIGROK, W. European cross-national production networks in the auto industry: eastern europe as the low end of european car complex. In: Kreisky Forum and BRIE Policy Conference, 1997.

VANALLE, R. M.; SALLES, J. A. A. Relação entre montadoras e fornecedores: modelos teóricos e estudos de caso na indústria automobilística brasileira. Gestão e Produção, v. 18, n. 2, p 237-250, 2011. http://dx.doi.org/10.1590/S0104-530X2011000200002

VIANA, F. L. E.; NETO, J. P. B.; AÑEZ, M. E. M. Gestão da cadeia de suprimento e vantagem competitiva: um modelo de análise a partir da teoria baseada em recursos.

Revista Ciências Administrativas, v. 20, n. 1, 2014.

http://dx.doi.org/10.5020/2318-0722.20.1.\%p

VOLLMANN, T. E.; BERRY, W. L.; WHYBARK, D. C.; JACOBS, F. R. Sistema de planejamento e controle da produção para o gerenciamento da cadeia de suprimentos. 5. ed. Porto Alegre: Bookman, 2006.

VOSS, C.; TSIKRIKTSIS, N.; FROHLICH, M. Case research in operations management. International Journal of Operations \& Production Management, v. 22, n. 2, p. 195-219, 2002. http://dx.doi.org/10.1108/01443570210414329

YIN, R. K. Estudo de caso: planejamento e métodos. 3. ed. Porto Alegre: Bookman, 2005.

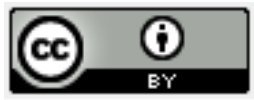

Artigo recebido em 22/02/2017 e aceito para publicação em 05/11/2017

DOI: http://dx.doi.org/10.14488/1676-1901.v17i4.2738 